\title{
A Combination of Pharmacophore Modeling, Molecular Docking and Virtual Screening Study Reveals 3,5,7-Trihydroxy-2-(3,4,5-trihydroxyphenyl)- 4H-Chromen-4-One as a Potential Anti-Cancer Agent of COT Kinase
}

\author{
Afzal Hussain*, Chandan Kumar Verma \\ Department of Bioinformatics, MANIT, Bhopal, Madhya Pradesh, INDIA.
}

\begin{abstract}
Background: COT (Tpl2/MAP3K8) is a Serine/ Threonine protein kinase which plays a crucial role in the production of TNF-alpha through the phosphorylation of MEK, ERK pathway and the production of other pro-inflammatory cytokines. Its inhibition has been shown as important to reduce inflammatory diseases and cancer. Material and Methods: Combined Ligand-based and Structure-based pharmacophore model was developed for finding out the potential anticancer agents. These combined pharmacophore model was used as 3D-query for searching the matching pharmacophore features against chemical structure databases such as DrugBank, MDPI, ZINC, Maybridge HitFinder. Docking was performed using Schrodinger software as well as selected Hits were filtered by ADMET properties. Results: Among all the selected Hits Compound 3,5,7-trihydroxy-2-(3,4,5trihydroxyphenyl)-4H-chromen-4-one was found to be more potent according to the docking score. Conclusion: A step by step computational pipeline was used to find out the potential anticancer agents. This study suggests that these Hits could be used as anticancer agents against death leading diseases.
\end{abstract}

Key words: COT Kinase, Docking, Pharmacophore model, Anticancer, LigandScout.

\section{INTRODUCTION}

Protein kinases shows its important role in the cellular functioning process. They take part in the various processes such as transcription, cell division, controlling the metabolism, cell movement, immune response, nervous system functioning. Kinase dysfunction is related to many diseases like cancer as well as inflammatory. ${ }^{1,2,3}$ The COT (Cancer Osaka Thyroid Kinase) kinase is a Mitogen Activated Protein Kinase 8 (MAP3K8). In the unstimulated cells, it makes a heterotrimeric complex with NF-kB-1 precursor protein p105 and the ubiquitin-binding protein $\mathrm{ABIN}-2$, when stimulation came with various inflammatory stimuli like Lipopolysaccharide (LPS), TNFreceptor 1, TNF, CD40 ligand through
Toll-Like Receptors (TLRs), CD40 and interleukin receptor (IL-1), it activates IKKB, which triggers the proteasomal degradation of the 105 and releases the ABIN-2 from the association of the p105 and COT. Activation of the COT involve to regulate various downstream inflammatory pathways including ERK, MEK, JNK, p38 $8^{4-7}$ (Figure 1).

After a vast literature survey it has been confirmed the role of the COT kinase in diverse diseases like high grade serious ovarian carcinoma, ${ }^{8}$ Acetaminophen-induced liver injury, ${ }^{9}$ Adipose tissue dysfunction in obesity, ${ }^{10}$ Breast cancer, ${ }^{11-14}$ Pancreatic and lung inflammation during acute pancreatitis, ${ }^{15}$
Submission Date: 07-11-2017 Revision Date: 05-12-2017; Accepted Date: 18-04-2018

DOI: 10.5530/ijper.52.4.81 Correspondence: Afzal Hussain, Department of Bioinformatics, MANIT, Bhopal, Madhya Pradesh 462003, INDIA. Phone: +919893916826 E-mail: ahussain591@gmail. com

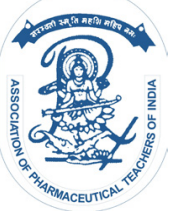

www.ijper.org 
Metastasis of clear cell renal cell carcinoma, ${ }^{16}$ ADI prostate cancer, ${ }^{17}$ Obesity induced adipose tissue inflammation, ${ }^{18}$ Papillary thyroid cancer, ${ }^{2}$ Multiple sclerosis. ${ }^{19}$ There are so many inhibitors have been identified to reduce the harmful effect of the COT kinase such as (E)-3-(2-amino5-(naphthalen-2-yl) pyridin-3-yl)acrylicacid, 5-(5-(1H-indol-3-yl)-1H-pyrrolo[2,3-b]pyridin3-yl)-1,3,4-oxadiazol-2-amine,5-(2-amino-5-(quinolin3 -yl)pyridin-3-yl)-1,3,4-oxadiazole-2(3H)-thione, ${ }^{20}$ 4-alkylamino-(1,7) naphthyridine-3-carbonitriles, ${ }^{21}$ Indazoles, ${ }^{22}$ 1,7-naphthyridine-3-carbonitriles, ${ }^{23}$ thieno $(2,3$-c) pyridine, ${ }^{24,25} 8$-substituted-4-anilino-6-aminoquinoline3-carbonitriles. ${ }^{26}$

So there is a need to find out the small molecule cancer drugs. ${ }^{27,28}$ The main aim of this study to design a systematic approach for the discovery of novel inhibitors searching out of Drug Databases. Ligand Based and Structure-based Pharmacophore model was generated with the help of LigandScout 3.12 and Schrodinger Software, This Pharmacophore model was used as 3-D query to search novel inhibitory compounds using diverse databases like ZINC, DrugBank, MDPI, Maybridge HitFinder. After getting the selected Hits, were subjected for the docking studies. 10 top Hits were identified, among them only four hits shows best characterstics and docking score more than previous reported compound. Compound (Hit 1) 3,5,7-trihydroxy-2-(3,4,5trihydroxyphenyl)-4H-chromen-4-one was found as most potent compound may be further used in the designing a new scaffold lead-like molecule for COT kinase inhibition. ${ }^{29-43}$

\section{MATERIALS AND METHODS}

\section{The Generation of the Ligand-Based Pharmacophore Model}

The common features based pharmacophore model was developed using three best Co-crystallized ligand found in the protein data bank in the complex form with the target. LigandScout (two training and one test ligand pharmacophore) and Schrodinger software tool (one ligand pharmacophore) was used, which develop the pharmacophore model in the most approapriate way. This Pharmacophore model was used as 3D query for searching out the matching pharmacophore Hits from diverse databases [DrugBank, MDPI, ZINC, Maybridge HitFinder]. ${ }^{29,30,32,44,45}$ The model was represented in Figure 2.

\section{Generation of Structure-Based Pharmacophore model}

The Structure-Based pharmacophore model was generated using the Protein (PDBID: 4Y83). The protein structure

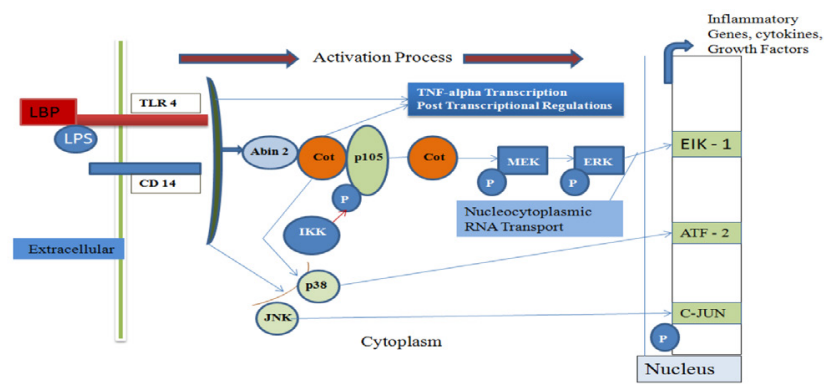

Figure 1: Activation mechanism of the COT kinase which further activate the downstream signaling pathway MEK and ERK.

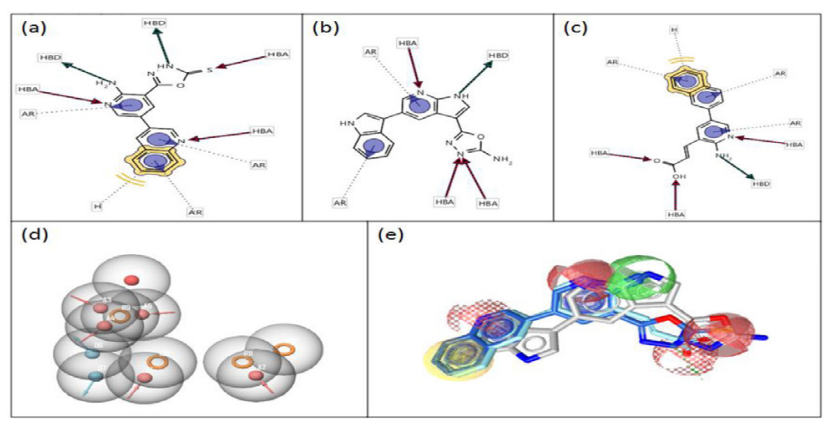

Figure 2: Generation of the Ligand-Based Pharmacophore model.

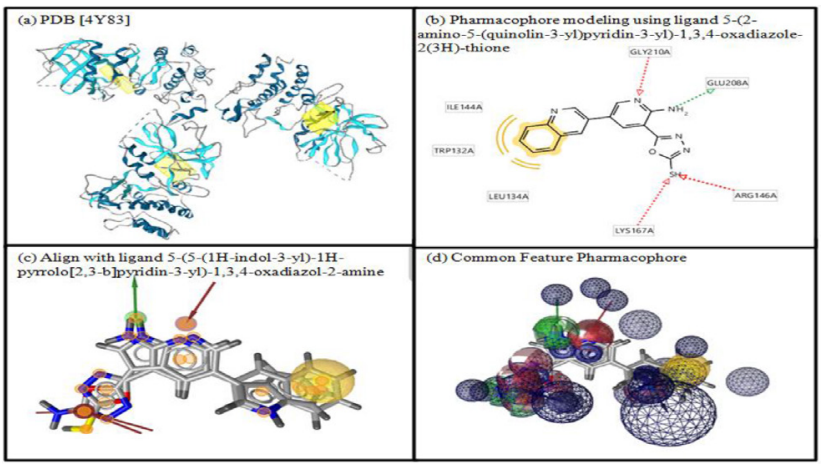

Figure 3: Generation of the Structure-Based Pharmacophore model.

was downloaded which contain the Ligand. The ligandprotein interaction residues chemical features were selected. We applied LigandScout 3.12 software for generating the pharmacophore model which contain all the chemical features information such as Hydrogen bond donors, Hydrogen bond acceptors, Hydrophobic residues within the binding site sphere of the receptors. ${ }^{32,34,43}$ It was shown in Figure 3.

\section{Pharmacophore Feature Matching Screening}

Drug database screening is a very crucial Bioinformatics technique for the drug discovery process in the medicinal chemistry research. We developed Ligand based and 
Structure based pharmacophore model, subjected against the commercially existing databases using LigandScout and Schrodinger software (Phase module) for Matching the pharmacophore features with the drug databases available drugs. ${ }^{29,34,45}$

\section{Ligand-Protein preparation and Docking Protein Preparation}

The target protein structure with inhibitor (PDBID: 4Y83) was downloaded from Protein data bank. Schrodinger software Prep wizard was used to prepare the structure, where bond orders were assigned and hydrogen atoms were added and in the last stage of preparation, restrained minimization was performed with OPLS-2005 force field and RMSD cut off was kept as $0.30 \mathrm{~A}^{020}$.

\section{Ligand Preparation}

Pharmacophore matched Hits were retrieved and exported as .sdf file and prepared by using LigPrep module of the Schrodinger software. In the preparation process the bond angle and the bond order were assigned. The minimization was done using OPLS-2005 force field and used Epik option for keeping ligand in the correct protonation state. ${ }^{46}$

\section{Grid Preparation}

The grid of the selected target structure was prepared by using the Glide protocol of the Schrodinger software. The crystallized inhibitor binding site was selected as centroid for the COT kinase and partial charge cutoff was kept as 0.25 . The scaling factor was chosen as 1.0 correspondingly. ${ }^{47}$

\section{Preparation of the Reference Compound}

The Crystallized inhibitor with the target was retrieved from the PDB (PDBID:4Y83). The inhibitor was also prepared by using the LigPrep module of the Schrodinger software and docked with the COT kinase to find out the binding interaction and docking score, which can be use further as reference score for finding out the potential Hits form MDPI, DrugBank, ZINC and Maybridge HitFinder databases.

\section{Docking}

The selected pharmacophore features matching Hits were further subjected for docking using Glide maestro virtual screening protocol. These selected compounds were filtered by Lipinski rule. The pre-reported inhibitor (reference compound) was also incorporated with these compounds. The docking (virtual screening workflow) was performed using HTVS, SP and XP steps against the target protein. ${ }^{41}$ The workflow was shown in Figure 4.

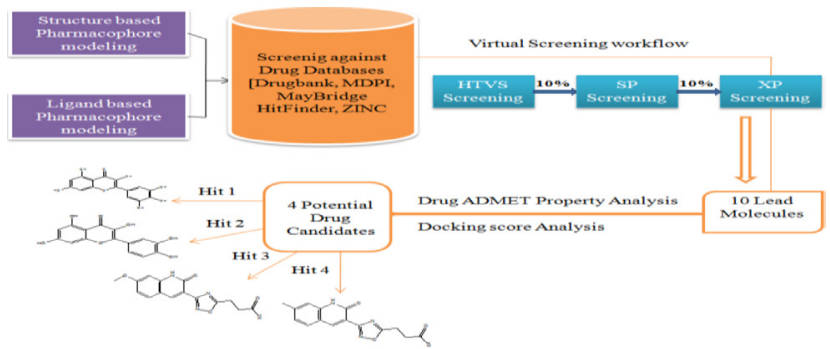

Figure 4: Pharmacophore feature matching screening using LigandScout, Phase and Docking using Schrodinger Software.

\section{Drug like property analysis}

The selected Hits were chosen for drug like properties analysis. These properties contain Lipinski's rule of five and diverse properties such as Molecular Weight (MW), Hydrogen Bond Donor (HBD), Hydrogen Bond Acceptor (HBA), Lipophilicity (log P), Human Oral Absorption. The other drug like properties which is also very crucial was selected like Total Solvent Accessible Surface Area, Predicted Aqueous Solubility, Predicted Polarizability, Predicted hexadecane/gas partition coefficient, Predicted water/gas partition coefficient, Predicted octanol/water partition coefficient, Predicted octanol/gas partition coefficient, Conformation-independent predicted aqueous solubility. Predicted skin permeability, log Kp, Prediction of binding to human serum albumin. ${ }^{48}$

\section{ADMET profiling analysis}

The ADMET property analysis is extremely significant for evaluating the Pharmacodynamic activities of the Hit compounds. The ADMET properties are associated with Absorption, Distribution, Metabolism, Excretion and Toxicity which was calculated by using Bioinformatics tool admetSAR (http://lmmd.ecust.edu.cn/admetsar1/ predict/). ${ }^{49}$

\section{RESULTS AND DISCUSSION}

\section{Pharmacophore Feature Matching Screening and Docking against the Target}

Novel Hits were identified by using the Pharmacophore feature matching screening and docking. Diverse drug databases like [MDPI, DrugBank, ZINC, Maybridge HitFinder] were used for getting the Hits. Ligand based and Structure based generating Pharmacophore model, which was further used as a 3D-query for screening against the drug databases. A limited number of potential Hits were identified, showed features like pharmacophore model. All the selected Hits were incorporated in the Schrodinger software for docking. Total 4 potential, specific Hits were identified which showed best binding 

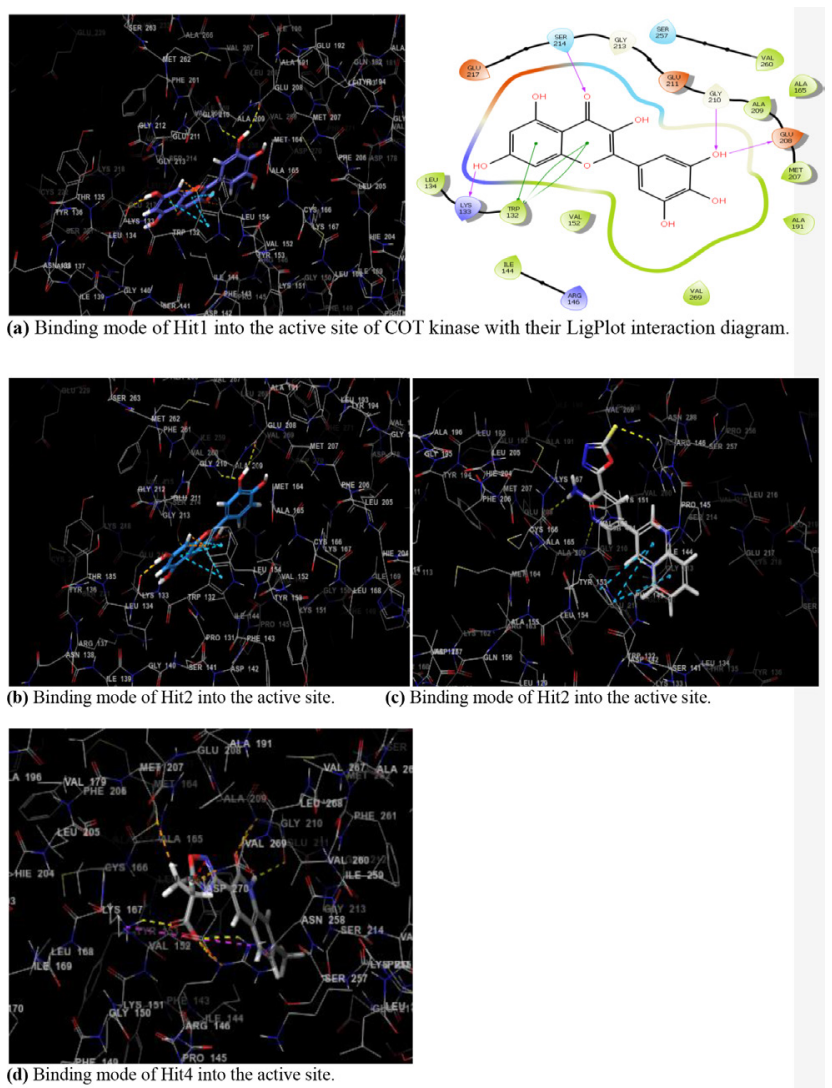

Figure 5: (a) Binding mode of Hit1 into the active site of COT kinase with their LigPlot interaction diagram. Respectively binding mode of (b) Hit2, (c) Hit3, (d) Hit4, The Hits were showed in the stick form and the yellow dotted lines indicated Hit-Target $\mathrm{H}$-bonding. The critical active protein residues showed in white color.

interaction with the target protein. Hit 1 3,5,7-trihydroxy-2-(3,4,5-trihydroxyphenyl)-4H-chromen-4-one was found as a most potent Hit, showed interaction with the active binding site of the target protein. It showed Hydrogen bond interaction with the residues (GLU 208, GLY 210, LYS 133, SER 214), Pi-Pi stacking with TRP 132 and the docking score is (-12.349). The docking score is high, first Hit showed tight interaction with the target with good inhibition characteristics. The docking score for all the selected Hits were identified (Table 1). Docking with LigPlot interaction diagram gives a better presentation of binding between the target and the Hit compounds (Figure 5).

\section{Drug-likeliness property analysis}

Drug like features (Lipinski's rule of five) of the selected best Hits were confirmed using Drug-likeliness property analysis. A good drug is always contain properties such as well distributed throughout the system, absorbed in the timeline as well as shows good metabolism property. QikProp tool of the Schrodinger software was used for this study. We have selected some properties which always give more impact like Human Oral Absorption, Molecular Weight (MW), Hydrogen bond donor (HBD), Hydrogen bond acceptor (HBA), Total Solvent Accessible Surface, Predicted Aqueous Solubility (QP $\log$ S). Additional Properties were also identified like Predicted Polarizability (QPpolrz), Total Solvent Accessible Surface Area (SASA), Predicted octanol/water partition coefficient (QPlogPo/w), Predicted hexadecane/gas partition coefficient (QPlogPC16), Predicted octanol/gas partition coefficient (QPlogPoct), Predicted water/gas partition coefficient (QPlogPw), Prediction of binding to human serum albumin (QPlogKhsa), Predicted skin permeability (QPlogKp), Lower the value of molecular weight is one of the favorable characteristics for drug like properties.

Total four potential Hits with their Drug-like properties were presented in Table 2.

\section{ADMET Prediction for selected screened Hits}

ADMET prediction for selected best Hits were performed using admetSAR server. BBB probability, Caco- 2 probability as well as HIA probability indicates good value where $\mathrm{BBB}$ represents the blood brain barrier, Higher the value of $\mathrm{BBB}$ represent better penetration, HIA (Human intestinal absorption) score is high shows better absorbance in the intestinal tract upon oral administration. Hits were mutagenic or not was confirmed by AMES test. Table 3. Prediction the efflux by P-glycoprotein (P-gp) metabolism of the selected best Hit compounds were carried out by a family of microsomal enzymes CYP-3A4, CYP-2C9, CYP-1A2 and CYP-2C19 shown in Table 4.

\section{Superimpose Structure}

Superimpose is a way where we can identify that the selected best Hits occupied the same binding sites or not. All the selected best Hits were superimposed and we found that the binding patterns were similar to the active site crystallized inhibitor.

\section{CONCLUSION}

A step by step computational pipeline was used to find out the potential anticancer agents. Ligand and structure based pharmacophore model was developed as 3-D query and Drugbank, MDPI, ZINC, Maybridge HitFinder drug databases were subjected for the screening process against the target (COT kinase) in a very rapid manner and docking was performed using Schrodinger software. Drug likeliness analysis, ADMET analysis was done with the help of admetSAR and QikProp. Total 4 best Hits were found promising and showed potential inhibitory characterstics. Hit 1 (3,5,7-trihydroxy-2-(3,4,5- 


\begin{tabular}{|c|c|c|c|c|}
\hline Compound & Compound Structure & $\begin{array}{l}\text { Mol. } \\
\text { Wt. }\end{array}$ & $\begin{array}{c}\text { Mol. } \\
\text { Formula }\end{array}$ & $\begin{array}{l}\text { Docking } \\
\text { Score }\end{array}$ \\
\hline Hit 1 & & 318.235 & $\mathrm{C}_{15} \mathrm{H}_{10} \mathrm{O}_{8}$ & -12.349 \\
\hline Hit 2 & & 302.236 & $\mathrm{C}_{15} \mathrm{H}_{10} \mathrm{O}_{7}$ & -11.839 \\
\hline Hit 3 & & 314.273 & $\mathrm{C}_{15} \mathrm{H}_{12} \mathrm{~N}_{3} \mathrm{O}_{5}^{-}$ & -11.330 \\
\hline Hit 4 & & 298.274 & $\mathrm{C}_{15} \mathrm{H}_{12} \mathrm{~N}_{3} \mathrm{O}_{4}^{-}$ & -11.258 \\
\hline Hit 5 & & 362.425 & $\mathrm{C}_{21} \mathrm{H}_{22} \mathrm{~N}_{4} \mathrm{O}_{2}$ & -10.796 \\
\hline Hit 6 & & 250.28 & $\mathrm{C}_{10} \mathrm{H}_{16} \mathrm{~N}_{7} \mathrm{O}+$ & -10.782 \\
\hline Hit 7 & & 312.301 & $\mathrm{C}_{16} \mathrm{H}_{14} \mathrm{~N}_{3} \mathrm{O}_{4}^{-}$ & -10.620 \\
\hline Hit 8 & & 284.263 & $\mathrm{C}_{16} \mathrm{H}_{12} \mathrm{O}_{5}$ & -10.493 \\
\hline Hit 9 & & 312.317 & $\mathrm{C}_{18} \mathrm{H}_{16} \mathrm{O}_{5}$ & -10.388 \\
\hline Hit 10 & & 328.316 & $\mathrm{C}_{18} \mathrm{H}_{16} \mathrm{O}_{6}$ & -10.319 \\
\hline $\begin{array}{c}\text { 5-(2-amino-5-(quinolin-3-yl) } \\
\text { pyridin-3-yl)-1,3,4-oxadiazole- } \\
\text { 2(3H)-thioner }\end{array}$ & - & - & - & -11.1403 \\
\hline
\end{tabular}

$r=$ Reference ligand 
Table 2: Drug-like properties analysis of the selected best Hits.

\begin{tabular}{|c|c|c|c|c|c|c|c|}
\hline S. No. & Compound Id & $\begin{array}{c}\text { Mol. } \\
\text { Wt. }\end{array}$ & SASA $^{\mathbf{b}}$ & $\begin{array}{c}\text { Human } \\
\text { Oral Absorption }^{\mathbf{d}}\end{array}$ & $\begin{array}{c}\text { HB } \\
\text { donor }^{\mathbf{e}}\end{array}$ & $\begin{array}{c}\text { HB } \\
\text { acceptor }^{\mathbf{f}}\end{array}$ & $\begin{array}{c}\text { QP } \\
\text { log Sg }^{\mathbf{g}}\end{array}$ \\
\hline 1. & Hit 1 & 318.235 & 527.917 & 26.816 & 5 & 6 & -2.635 \\
\hline 2. & Hit 2 & 302.236 & 515.473 & 51.557 & 4 & 5 & -2.852 \\
\hline 3. & Hit 3 & 314.273 & 541.307 & 57.245 & 2 & 8 & -2.855 \\
\hline 4. & Hit 4 & 298.274 & 558.556 & 57.595 & 2 & 8 & -3.481 \\
\hline
\end{tabular}

acompound

bolecular weight (acceptable range is: $\leq 500$ )

'Total solvent accessible surface area (acceptable range is: 300-1000)

dHuman oral absorption (acceptable range is: $<25 \%$ less and $>80 \%$ high)

eHydrogen bond donor (acceptable range is: $\leq 5$ )

fHydrogen bond acceptor (acceptable range is: $\leq 10$ )

gPredicted aqueous solubility (acceptable range is: $-6.5-0.5$ )

\begin{tabular}{|c|c|c|c|c|c|c|c|c|c|}
\hline S. No. & Compound & QPpolrz & QPlogPC16 & QPlogPoct & QPlogPw & QPlogPo/w & ClQPlogS & QPlogKp & QPlogKhsa \\
\hline 1. & Hit 1 & 27.331 & 11.233 & 20.570 & 16.490 & -0.307 & -4.011 & -6.443 & -0.489 \\
\hline 2. & Hit 2 & 27.406 & 10.718 & 18.618 & 14.393 & 0.352 & -4.043 & -5.557 & -0.344 \\
\hline 3. & Hit 3 & 30.160 & 9.969 & 18.681 & 13.761 & 0.952 & -3.337 & -4.478 & -0.648 \\
\hline 4. & Hit 4 & 31.107 & 10.029 & 17.809 & 13.351 & 1.205 & -3.307 & -4.686 & -0.496 \\
\hline
\end{tabular}

- QPplorz Predicted polarizability in cubic angstroms (acceptable range is: 13.0-70.0)

- QPlogPC16 Predicted hexadecane/gas partition coefficient (acceptable range is: $4.0-18.0$ )

- QPlogPoct Predicted octanol/gas partition coefficient (acceptable range is: $8.0-35.0$ )

- $\quad$ QPlogPw Predicted water/gas partition coefficient (acceptable range is: 4.0 - 45.0)

- OplogPo/w Predicted octanol/water partition coefficient (acceptable range is: $-2.0-6.5$ )

- CIQPlogS Conformation-independent predicted aqueous solubility, log S. S in mol dm-3 is the concentration of the solute in a saturated solution that is in equilibrium with the crystalline solid (acceptable range is: $-6.5-0.5$ )

- $\quad$ QPlogKp Predicted skin permeability, log Kp (acceptable range is: $-8.0-1.0$ )

- QPlogKhsa Prediction of binding to human serum albumin (acceptable range is: $-1.5-1.5$ )

Table 3: In-Silico absorption and toxicity analysis using admetSAR server.

\begin{tabular}{|c|c|c|c|c|c|c|c|}
\hline S.No. & Compound & BBB Probability & HIA Probability & $\begin{array}{c}\text { Caco-2 } \\
\text { Probability }\end{array}$ & $\begin{array}{c}\text { AMES } \\
\text { Test }\end{array}$ & Carcinogenicity & $\begin{array}{l}\text { Rat acute toxicity } \\
\text { (LD50:mol/kg) }\end{array}$ \\
\hline 1. & Hit 1 & 0.5711 & 0.9650 & 0.8957 & Non-toxic & Non-carcinogens & 3.0200 \\
\hline 2. & Hit 2 & 0.5711 & 0.9650 & 0.8957 & Non-toxic & Non-carcinogens & 3.0200 \\
\hline 3. & Hit 3 & 0.7307 & 0.9768 & 0.5801 & toxic & Non-carcinogen & 2.4586 \\
\hline 4. & Hit 4 & 0.8169 & 0.9878 & 0.6126 & Non-toxic & Non-carcinogens & 2.3709 \\
\hline
\end{tabular}

Table 4: Prediction the efflux by P-glycoprotein (P-gp) metabolism of the best Hit compounds.

\begin{tabular}{|c|c|c|c|c|c|c|c|c|}
\hline S.No. & Compound & $\begin{array}{c}\text { P-gp substrate/ } \\
\text { Inhibitor } \\
\text { Probability }\end{array}$ & $\begin{array}{l}\text { CYP-2C9 } \\
\text { substrate/ } \\
\text { Inhibitor }\end{array}$ & $\begin{array}{l}\text { CYP-2D6 } \\
\text { substrate/ } \\
\text { Inhibitor }\end{array}$ & $\begin{array}{l}\text { CYP-3A4 } \\
\text { substrate/ } \\
\text { Inhibitor }\end{array}$ & $\begin{array}{l}\text { CYP-1A2 } \\
\text { substrate/ } \\
\text { Inhibitor }\end{array}$ & $\begin{array}{c}\text { CYP- } \\
\text { 2C19 } \\
\text { Inhibitor }\end{array}$ & $\begin{array}{c}\text { CYP } \\
\text { inhibitory } \\
\text { promiscuity }\end{array}$ \\
\hline 1. & Hit 1 & $\begin{array}{l}\text { substrate/ Non- } \\
\text { Inhibitor }\end{array}$ & $\begin{array}{l}\text { Non-substrate/ } \\
\text { Non-Inhibitor }\end{array}$ & $\begin{array}{l}\text { Non-substrate/ } \\
\text { Non-Inhibitor }\end{array}$ & $\begin{array}{c}\text { Non-substrate/ } \\
\text { Inhibitor }\end{array}$ & Inhibitor & $\begin{array}{c}\text { Non- } \\
\text { Inhibitor }\end{array}$ & High \\
\hline 2. & Hit 2 & $\begin{array}{l}\text { substrate/ Non- } \\
\text { Inhibitor }\end{array}$ & $\begin{array}{l}\text { Non-substrate/ } \\
\text { Non-Inhibitor }\end{array}$ & $\begin{array}{l}\text { Non-substrate/ } \\
\text { Non-Inhibitor }\end{array}$ & $\begin{array}{c}\text { Non-substrate/ } \\
\text { Inhibitor }\end{array}$ & Inhibitor & $\begin{array}{c}\text { Non- } \\
\text { Inhibitor }\end{array}$ & High \\
\hline 3. & Hit 3 & $\begin{array}{l}\text { Non-substrate/ } \\
\text { Non-Inhibitor }\end{array}$ & $\begin{array}{l}\text { Non-substrate/ } \\
\text { Inhibitor }\end{array}$ & $\begin{array}{l}\text { Non-substrate/ } \\
\text { Non-Inhibitor }\end{array}$ & $\begin{array}{l}\text { substrate/ } \\
\text { Inhibitor }\end{array}$ & Inhibitor & Inhibitor & High \\
\hline 4. & Hit 4 & $\begin{array}{l}\text { Non-substrate/ } \\
\text { Non-Inhibitor }\end{array}$ & $\begin{array}{c}\text { Non-substrate/ } \\
\text { Non-Inhibitor }\end{array}$ & $\begin{array}{l}\text { Non-substrate/ } \\
\text { Non-Inhibitor }\end{array}$ & $\begin{array}{l}\text { substrate/ } \\
\text { Non-Inhibitor }\end{array}$ & Inhibitor & $\begin{array}{c}\text { Non- } \\
\text { Inhibitor }\end{array}$ & High \\
\hline
\end{tabular}


trihydroxyphenyl)-4H-chromen-4-one) was found most potent and selective and showing better interaction as well as high docking score. This study suggests that these Hits could be used as anticancer agents against death leading diseases.

\section{CONFLICT OF INTEREST}

The authors declare no conflict of interest.

\section{ABBREVIATIONS}

COT: Cancer Osaka Thyroid Kinase; MDPI: Molecular Diversity Preservation International; BBB: Blood Brain Barrier; HIA: Human Intestinal Absorption; HTVS: High-throughput Virtual Screening; SP: Standard-precision; XP: Extra-precision.

\section{REFERENCES}

1. Roskoski R. Jr. A historical overview of protein kinases and their targeted small molecule inhibitors. Pharmacol Res. 2015;100:1-23.

2. Lee J, Jeong S, Park JH, Lee CR, Ku CR, Kang SW, et al. Aberrant expression of COT is related to recurrence of papillary thyroid cancer. Medicine. 2015;94(6):e548.

3. London CA. Kinase dysfunction and kinase inhibitors. Vet Dermatol. 2013;24(1):181-7. e39-40.

4. Gantke T, Sriskantharajah S, Sadowski M, Ley SC. IkappaB kinase regulation of the TPL-2/ERK MAPK pathway. Immunol Rev. 2012;246(1):168-82.

5. Beinke S, Robinson MJ, Hugunin M, Ley SC. Lipopolysaccharide activation of the TPL-2/MEK/extracellular signal-regulated kinase mitogen-activated protein kinase cascade is regulated by IkappaB kinase-induced proteolysis of NF-kappaB1 p105. Mol Cell Biol. 2004;24(21):9658-67.

6. Lee HW, Choi HY, Joo KM, Nam DH. Tumor progression locus 2 (Tpl2) kinase as a novel therapeutic target for cancer: double-sided effects of Tpl2 on cancer. Int J Mol Sci. 2015;16(3):4471-91.

7. Gantke T, Sriskantharajah S, Ley SC. Regulation and function of TPL-2, an IkappaB kinase-regulated MAP kinase kinase kinase. Cell Res. 2011;21(1):131-45.

8. Gruosso T, Garnier C, Abelanet S, Kieffer Y, Lemesre V, Bellanger D, et al. MAP3K8/TPL-2/COT is a potential predictive marker for MEK inhibitor treatment in high-grade serous ovarian carcinomas. Nat Commun. 2015;6:8583.

9. Sanz-Garcia C, Ferrer-Mayorga G, Gonzalez-Rodriguez A, Valverde AM, Martin-Duce A, Velasco-Martin JP, et al. Sterile inflammation in acetaminophen-induced liver injury is mediated by Cot/tpl2. J Biol Chem. 2013;288(21):15342-51.

10. Jager J, Gremeaux T, Gonzalez T, Bonnafous S, Debard C, Laville M, et al. Tpl2 kinase is upregulated in adipose tissue in obesity and may mediate interleukin-1beta and tumor necrosis factor-\{alpha\} effects on extracellular signal-regulated kinase activation and lipolysis. Diabetes. 2010;59(1):61-70.

11. Krcova Z, Ehrmann J, Krejci V, Eliopoulos A, Kolar Z. Tpl-2/Cot and COX-2 in breast cancer. Biomed Pap Med Fac Univ Palacky Olomouc Czech Repub. 2008;152(1):21-5.

12. Kim JY, Lim SC, Kim G, Yun HJ, Ahn SG, Choi HS. Interleukin-33/ST2 axis promotes epithelial cell transformation and breast tumorigenesis via upregulation of COT activity. Oncogene. 2015;34(38):4928-38.

13. Sourvinos G, Tsatsanis C, Spandidos DA. Overexpression of the Tpl-2/Cot oncogene in human breast cancer. Oncogene. 1999;18(35):4968-73.

14. Kim G, Khanal P, Kim JY, Yun HJ, Lim SC, Shim JH, et al. COT phosphorylates prolyl-isomerase Pin1 to promote tumorigenesis in breast cancer. Mol Carcinog. 2015;54(6):440-8.
15. Van Acker GJ, Perides G, Weiss ER, Das S, Tsichlis PN, Steer ML. Tumor progression locus-2 is a critical regulator of pancreatic and lung inflammation during acute pancreatitis. J Biol Chem. 2007;282(30):22140-9.

16. Lee HW, Joo KM, Lim JE, Cho HJ, Cho HJ, Park MC, et al. Tpl2 kinase impacts tumor growth and metastasis of clear cell renal cell carcinoma. Mol Cancer Res. 2013;11(11):1375-86.

17. Jeong JH, Bhatia A, Toth Z, Oh S, Inn KS, Liao CP, et al. TPL2/COT/MAP3K8 (TPL2) activation promotes androgen depletion-independent (ADI) prostate cancer growth. PloS one. 2011;6(1):e16205.

18. Ballak DB, van Essen $P$, van Diepen JA, Jansen $H$, Hijmans A, Matsuguchi T, et al. MAP3K8 (TPL2/COT) affects obesity-induced adipose tissue inflammation without systemic effects in humans and in mice. PloS one. 2014;9(2):e89615.

19. Sriskantharajah S, Guckel E, Tsakiri N, Kierdorf K, Brender C, Ben-Addi A, et al. Regulation of experimental autoimmune encephalomyelitis by TPL-2 kinase. J Immunol. 2014;192(8):3518-29.

20. Gutmann S, Hinniger A, Fendrich G, Druckes P, Antz S, Mattes H, et al. The Crystal Structure of Cancer Osaka Thyroid Kinase Reveals an Unexpected Kinase Domain Fold. J Biol Chem. 2015;290(24):15210-8.

21. Kaila N, Green N, Li HQ, Hu Y, Janz K, Gavrin LK, et al. Identification of a novel class of selective Tpl2 kinase inhibitors: 4-Alkylamino-[1, 7] naphthyridine-3carbonitriles. Bioorg Med Chem. 2007;15(19):6425-42.

22. Hu Y, Cole D, Denny RA, Anderson DR, Ipek M, Ni Y, et al. Discovery of indazoles as inhibitors of Tpl2 kinase. Bioorg Med Chem lett. 2011;21(16):4758-61.

23. Gavrin LK, Green N, Hu Y, Janz K, Kaila N, Li HQ, et al. Inhibition of Tpl2 kinase and TNF-alpha production with 1,7-naphthyridine-3-carbonitriles: synthesis and structure-activity relationships. Bioorg Med Chem lett. 2005;15(23):5288-92.

24. George D, Friedman M, Allen $\mathrm{H}$, Argiriadi M, Barberis C, Bischoff A, et al. Discovery of thieno[2,3-c]pyridines as potent COT inhibitors. Bioorg Med Chem lett. 2008;18(18):4952-5

25. Cusack K, Allen H, Bischoff A, Clabbers A, Dixon R, Fix-Stenzel S, et al. Identification of a selective thieno[2,3-c]pyridine inhibitor of COT kinase and TNF-alpha production. Bioorg Med Chem lett. 2009;19(6):1722-5.

26. Green N, Hu Y, Janz K, Li HQ, Kaila N, Guler S, et al. Inhibitors of tumor progression loci-2 (Tpl2) kinase and tumor necrosis factor alpha (TNFalpha) production: selectivity and in vivo antiinflammatory activity of novel 8-substituted-4-anilino-6-aminoquinoline-3-carbonitriles. J Med Chem. 2007;50(19):4728-45.

27. Noble ME, Endicott JA, Johnson LN. Protein kinase inhibitors: insights into drug design from structure. Science. 2004;303(5665):1800-5.

28. Hoelder S, Clarke PA, Workman P. Discovery of small molecule cancer drugs: successes, challenges and opportunities. Mol Oncol. 2012;6(2):155-76.

29. Vuorinen A, Engeli R, Meyer A, Bachmann F, Griesser UJ, Schuster D, et al. Ligand-based pharmacophore modeling and virtual screening for the discovery of novel 17beta-hydroxysteroid dehydrogenase 2 inhibitors. J Med Chem. 2014;57(14):5995-6007.

30. Prasad NK, Kanakaveti V, Eadlapalli S, Vadde R, Meetei AP, Vindal V. Ligand-Based Pharmacophore Modeling and Virtual Screening of RAD9 Inhibitors. J Chem. 2013;2013:7.

31. Markt P, Schuster D, Kirchmair J, Laggner C, Langer T. Pharmacophore modeling and parallel screening for PPAR ligands. J Comput Aided Mol Des. 2007;21(10-11):575-90.

32. Wolber G, Dornhofer AA, Langer T. Efficient overlay of small organic molecules using 3D pharmacophores. J Comput Aided Mol Des. 2006;20(12):773-88.

33. Steindl TM, Schuster D, Wolber G, Laggner C, Langer T. High-throughput structure-based pharmacophore modelling as a basis for successful parallel virtual screening. J Comput Aided Mol Des. 2006;20(12):703-15.

34. Rella M, Rushworth CA, Guy JL, Turner AJ, Langer T, Jackson RM. Structurebased pharmacophore design and virtual screening for novel angiotensin converting enzyme 2 inhibitors. J Chem Inf Model. 2006;46(2):708-16.

35. Tuccinardi T. Docking-based virtual screening: recent developments. Comb Chem High Throughput screen. 2009;12(3):303-14.

36. Mclnnes $\mathrm{C}$. Virtual screening strategies in drug discovery. Curr Opin Chem Biol. 2007;11(5):494-502. 
37. Wieder M, Garon A, Perricone U, Boresch S, Seidel T, Almerico AM, et al. Common Hits Approach: Combining Pharmacophore Modeling and Molecular Dynamics Simulations. J Chem Inf Model. 2017;57(2):365-85.

38. Perricone $\mathrm{U}$, Wieder M, Seidel T, Langer T, Padova A, Almerico AM, et al A Molecular Dynamics-Shared Pharmacophore Approach to Boost EarlyEnrichment Virtual Screening: A Case Study on Peroxisome ProliferatorActivated Receptor alpha. ChemMedChem. 2017;12(16):1399-407.

39. Lei B, Heng N, Dang X, Liu J, Yao X, Zhang C. Structure based in silico identification of potentially non-steroidal brassinosteroids mimics. Mol BioSyst. 2017;13(7):1364-9.

40. Klimenko K, Lyakhov S, Shibinskaya M, Karpenko A, Marcou G, Horvath D, et al. Virtual screening, synthesis and biological evaluation of DNA intercalating antiviral agents. Bioorg Med Chem lett. 2017;27(16):3915-9

41. Hussain A. Molecular docking and in silico ADMET study reveals 3-(5-\{[4-(aminomethyl) piperidin-1-yl] methyl\}-1h-indol-2-yl)-1h-indazole-6carbonitrile as a potential inhibitor of cancer Osaka thyroid kinase. Biomed Res. 2017;28(13):5805-5815

42. Hochleitner J, Akram M, Ueberall M, Davis RA, Waltenberger B, Stuppner H, et al. A combinatorial approach for the discovery of cytochrome P450 2D6 inhibitors from nature. Sci Rep. 2017;7(1):8071.

43. Kaserer T, Beck KR, Akram M, Odermatt A, Schuster D. Pharmacophore Models and Pharmacophore-Based Virtual Screening: Concepts and
Applications Exemplified on Hydroxysteroid Dehydrogenases. Molecules. 2015;20(12):22799-832.

44. Dixon SL, Smondyrev AM, Rao SN. PHASE: a novel approach to pharmacophore modeling and 3D database searching. Chem Biol Drug Des. 2006;67(5):370-2.

45. Dixon SL, Smondyrev AM, Knoll EH, Rao SN, Shaw DE, Friesner RA. PHASE: a new engine for pharmacophore perception, 3D QSAR model development, and $3 \mathrm{D}$ database screening: 1 . Methodology and preliminary results. J Comput Aided Mol Des. 2006;20(10-11):647-71.

46. Banks JL, Beard HS, Cao Y, Cho AE, Damm W, Farid R, et al. Integrated Modeling Program, Applied Chemical Theory (IMPACT). J Comput Chem. 2005;26(16):1752-80.

47. Friesner RA, Murphy RB, Repasky MP, Frye LL, Greenwood JR, Halgren TA, et al. Extra precision glide: docking and scoring incorporating a model of hydrophobic enclosure for protein-ligand complexes. J Med Chem. 2006;49(21):6177-96.

48. Lipinski CA, Lombardo F, Dominy BW, Feeney PJ. Experimental and computational approaches to estimate solubility and permeability in drug discovery and development settings. Adv Drug Deliv Rev. 2001;46(1-3):3-26.

49. Yamashita F, Hashida M. in silico approaches for predicting ADME properties of drugs. Drug Metab Pharmacokinet. 2004;19(5):327-38.

\section{PICTORIAL ABSTRACT}

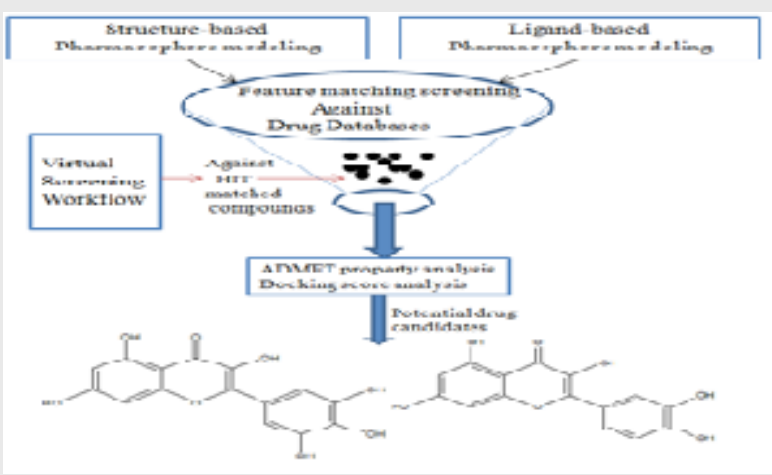

\section{SUMMARY}

COT kinase activation involve in cancer progression. Ligand-based and Structure-based pharmacophore model was developed for searching out the feature matching compounds.

Virtual screening was done and got potential hits which could be used as an anticancer agents in near future.

\section{About Authors}

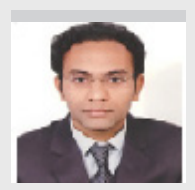

Afzal Hussain working as a Ph.D. Research Scholar in NIT, Bhopal. He worked in the field of medicinal chemistry using a bioinformatics approach for searching out novel anticancer agents as well as using advanced next-generation sequencing for analysis cancer gene expression. He has more than nine years experience in this field, in which he has found novel compounds for the specific kinases for reducing harmful death-leading effects

Afzal is currently collaborating with many organizations to design anti-inflammatory molecules against cancer. He has received the prestigious Young Scientist Award and has twice been the recipient of the Young Scientist Fellowship from the Ministry of Science and Technology, India, for showing their best involvement in research work. He has also worked in the Ministry of Science and Technology in Junior Research Fellow projects.

His scientific work has been published in high impact journals including the European Journal of Medicinal Chemistry, Biomedical Research and the SJBC. His areas of expertise include bioinformatics, drug designing, next-generation sequencing data analysis, and phylogenetic analysis.

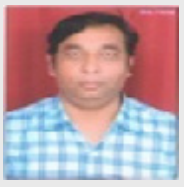

Dr. Chandan Kumar Verma is working as an Assistant Professor in M.A.N.I.T., Bhopal. He is having 15 years experience and 21 international publication in the reputed journals. He is having vast experience in the field of Bioinformatics data analysis, Microarray gene expression etc.

Cite this article: Hussain A, Verma CK. A Combination of Pharmacophore Modeling, Molecular Docking and Virtual Screening Study Reveals 3,5,7-Trihydroxy-2-(3,4,5-trihydroxyphenyl)-4H-Chromen-4-One as a Potential AntiCancer Agent of COT Kinase. Indian J of Pharmaceutical Education and Research. 2018;52(4):699-706. 